\title{
The humanities as allies: media studies and the web
}

\author{
Peter Dahlgren \\ Lund University \\ peter.dahlgren@kom.lu.se
}

\begin{abstract}
From the horizons of media and communication studies, this article begins with the premise that the media, and the in particular the Web, as central features of a turbulent late modernity. The Web has become ubiquitous and central to our sense of who we are, how we live, think, relate to others and experience the world. This process of mediatization is complex and historically without parallel; it affects all aspects of society, culture and politics. Most research on these developments are firmly based in the social sciences. The argument is made here that to fully grasp the implications of these transformations - which are even beginning to alter traditional noti-

ons of 'the human' - we would benefit from more assistance from the humanities. While acknowledging the difficult institutional position that the humanities find themselves in, the contention is that their intellectual perspectives are needed, especially in history, philosophy, and aesthetics. These could help us to better place the developments in broader contexts and illuminate what is at stake. The latter part of the article offers a set of themes that exemplify some of the key dilemmas that are emerging as the Web becomes all the more central to our lives dilemmas that would benefit from serious attention from the humanities.
\end{abstract}

\section{Preliminaries}

D ICKENS opens his A Tale of Two Cities with 'It was the best of times, it was the worst of times, it was the age of wisdom, it was the age of foolishness, it was the epoch of belief, it was the epoch of incredulity, it was the season of Light, it was the season of Darkness, it was the spring of hope, it was the winter of despair...' Today we are perched on another precarious historical fence, weighing the pros and cons of late modernity: all the material wealth and wellbeing are juxtaposed to increasing deprivation and social crises; there is an unease as we sense that our compelling technological progress is indeed proving to be a Faustian bargain - not least as we look at the state of the environment. We are not convinced that 'progress' has made us 'happier'.

A central feature of late modernity is the media, especially in their newer digital forms. These I conveniently (but somewhat inaccurately) here call the Web, as a shorthand to refer to the technical

A Revista Estudos em Comunicação é financiada por Fundos FEDER através do Programa Operacional Factores de Competitividade - COMPETE e por Fundos Nacionais através da FCT - Fundação para a Ciência e a Tecnologia no âmbito do projeto Comunicação, Filosofia e Humanidades (LabCom.IFP) UID/CCI/00661/2013.
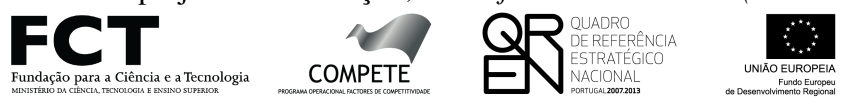

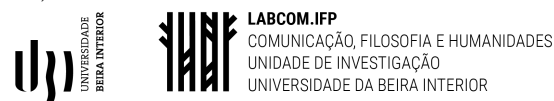


infrastructure of the Internet and the software of integrated digital media, including social media platforms. The Web is not only embedded as an inexorable manifestation of this age, it is also a force that contributes to driving it forward, particularly via the meta-processes of mediatization. As I explain below, this term posits that the media interplay with all dimensions of the social and cultural world, reorganizing how we live and experience our lives. I underscore that the dynamics of mediatization - and more specifically their consequences - are ambivalent. The rise of the Web as mass phenomena less than a quarter of a century ago has dramatically altered our lives, providing us with tools that would been unimaginable not long ago. With all the advantages, however, it manifests dark sides as well, thereby raising serious questions.

Most research with the field of Media and Communication Studies (or, Media Studies for short) is firmly anchored in the social sciences; there are some contributions from the humanities, but they remain a minority. The ulterior intension of this text is to invite more engagement from the humanities regarding the Web. My premise is that we as social scientists, and the field as whole, would greatly benefit from such engagement, as intellectual stimulation for the field. So why cannot the social sciences handle these issues largely on their own? Well, they can and they have, but in my view there are areas of inquiry where humanities perspectives could see things through different lenses and genuinely enhance our understanding, by posing other sorts of questions and perhaps pointing to different kinds of answers. Digital media are not only about how we do things, how we work, socialize, play, and get things done. With their ubiquity, they have also become central to our sense of who we are, and to how we experience and relate to the world - themes that the humanities could further probe in edifying ways, situating them in historical contexts, illuminating normative and aesthetic dimensions. Democracy, in turn, is not just about a formal system, its structures and dynamics. It is all about the people and their subjectivities, the values, and cultural patterns that sustain and permeate society.

In the presentation I begin with some brief reflections on why the humanities are important for Media Studies, while also acknowledging the difficult position in which the humanities find themselves. The question might be raised: why seek help from wounded allies? My view is that even if their institutional position is weak, their intellectual affordances are important, not least for media research. Moreover, I argue that their plight has relevance for democracy itself. From there I turn to the field of Media Studies and the emerging paradigm of mediatization, offering a short scene-setting for what follows. The next and central section looks at the Web, highlighting a number of key thematic areas that are persistently problematic. This is by no means an 'anti-Web tirade'; rather, my discussion is driven by a sense that with all the justifiable praise accorded the Web, some important questions are left in the shadows, including ones that begin to problematize traditional notions of 'the human'. It is here where more engagement from the humanities could offer some spotlights.

\section{Why the humanities?}

At bottom, the notion 'the humanities' encompasses both production within arts and culture - the generation of various kinds of 'works' - as well as the analysis of such production (e.g. literature and literary criticism). Our concern here resides largely with the analysis side of the 
humanities, although certain kinds of production, for example, philosophy, is also of considerable relevance. For those readers who have their anchoring within the humanities, the rubric of this section no doubt sounds redundant; for other readers, I wish to recapitulate a number of very traditional arguments. I do this with a starting point in a rather recent text by Holm, Scott and Jarrick (2014); their Humanities World Report 2015 is both a survey of the views of leading humanistic scholars from around the world as well as an original contribution to the contemporary discussions about the state of the humanities.

\section{Essential contributions}

The authors contend that the humanities make a number of essential contributions to people and societies all around the world (there is no fashionable 'cultural relativism' in their argument: they assert the significance of the humanities for everyone). They assert first of all the most classic view, that the humanities have an intrinsic value, in that they support personal and spiritual development, not least by fostering aesthetic appreciation. This of course has been the basic position for at least two and a half millennia. Bringing up the perspective to the contemporary world, they make the unassailable case that the humanities contribute to other disciplines, feeding into other fields, ranging from the social and natural sciences, to medicine, computer science, and engineering/design. The contributions can vary enormously, from illuminating implicit value premises in social research to elucidating the aesthetic parameters of an architectural design.

Further, Holm, Scott and Jarrick (2014) posit that the traditional benefits of the humanities now have an extra relevance in the context of heterogeneous societies: they have 'broad social value' in their striving to create tolerance and understanding between citizens, facilitating social cohesion. The pertinence of this needs hardly be defended in the context of our multifarious, multicultural societies, where living together with difference is proving to be an ever greater challenge. As an extension of this reasoning, they also underscore the importance of the humanities to enable citizens to understand, preserve, and not least - where necessary - to challenge national heritage and culture. This is to learn from the past about one's collective identities - to appreciate, appropriate - but also to confront and reject questionable elements that have shaped a shared sense of community. The relevance of this horizon is brought home not least as some right-wing political leaders in Europe today are striving to rewrite the history of their countries to promote a more politically expedient narrative, one that edits out uncomfortable historical realities from collective memory. In short, democratic life benefits from input from the humanities.

The report also sees the humanities as serving to aid decision-making on ethical issues, which are becoming all the more complex as social policies must take into account all the more intricate social contexts, and as technological developments demand all the more attentiveness to ethical dimensions and risk aspects, from genetic manipulation to nuclear power.

In case there was any lingering suspicion, the Humanities World Report 2015 makes it abundantly clear that the humanities should absolutely not be seen as some static body of truth or wisdom, even if they include some indispensable legacies. The humanities at bottom foster critical thinking. This is their essence; it epitomized by - but not limited to - the Socratic tradition. Rather, they manifest an ongoing critical dialogue and interrogation of circumstances, achieve- 
ments, and dilemmas of the human world, while they aim to understand, interpret, inspire, and challenge

\section{Critical thinking in a world of hazardous transitions}

The critical tradition of the humanities became incorporated into Enlightenment. The Enlightenment reaffirmed the basic view of the traditional humanities that questioning is essential for the growth of knowledge. Thus the idea of 'critical' has become an attribute associated with arts, science, and pursuit of knowledge. Moreover, the notion of 'critique' emerged as a more specific stance (I expand on these themes in Dahlgren 2013). Walter Benjamin suggests that critique involves brushing against the grain of established understandings. For Hegel, critique veered towards reflections on power relations, and challenges to domination - an intellectual thread that Marx most famously picked up and pursued. No less famous is Kant's notion of critique, in the sense of reflections on the conditions of our knowing: what are the contingencies that shape how we know the world and ourselves (in his Critique of Pure Reason)? Enlightenment for Kant becomes precisely the way out of our self-imposed ignorance.

Thus, this 'brushing against the grain', probing power relations, and reflecting on the factors that shape and inevitably delimit our knowledge, are essential toolkits for navigating the modern world, which often feels - and is - overwhelming. The future is not what it used to be, so to speak. Just looking at some of the major hazardous global transitions that we facing makes this apparent: climate and pollution trauma, economic-financial breakdowns, political crises, culture and religious collisions, failed states, and wars fill the news daily. This is generating not just uncertainty, but also fear, which is being politically exploited on many fronts. Spheres of human life previously separated by geography, class, normative horizons, domains of power, or expertise, are becoming ever more juxtaposed, intermingled, hybridized. Confusion is considerable. Yet, this 'liquid' character of late modernity (Bauman 2007), where values and ethics appear further dislodged from traditional perceived certainties, also offers us new opportunities to think afresh, to break new ground. We need philosophers, historians, text analysts: it is in the interplay with other fields that the humanities can make an extra contribution that other disciplines are less equipped to do. By questioning and offering critiques, they can enhance the growth of knowledge in their own fields as well as those with whom they enter into critical dialogue.

This stance of critique is important. However, it is not always clear to what extent it is operative. In regard, for example, to the new emerging hybrid filed of digital humanities (DH) Holm, Scott and Jarrick (2014) on the one hand laud the engagement and crossover between the humanities and computer science that DH represents. The benefits of DH are obvious: the analytic work of some humanities research can be made easier; with all vast cataloguing of materials that are going on, and it facilitates access in ways previous not possible. On the other hand, the authors find that despite all the helpful applications, DH does not seem to be critically dialoging with computer science; it is not generating much in the way of new research questions. They opine that DH must demonstrate its intellectual power and potential and promote new ways of thinking; in other words it must do more to generate critique. 


\section{The humanities under duress}

It is clear that all is not well with the humanities, unfortunatelty: their marginalization in higher education and in the allocation of research funding has been going on for many decades. I am in a sense appealing to assistance from potential allies who are wounded. In fact, one could argue that the 'humanities' have been in decline ever since the term became widespread in the academic world, which was after World War II. Prior to that, the usual rubric was 'Liberal Arts', 'Arts and Sciences', or 'Arts, Letters and Sciences' (Perloff, 2001). Some observers would go back even centuries earlier, others would set the start of the crisis in the 1960s. In any case, in the post-war era, the general societal drift that lauds 'utility', efficiency, and market logic has eroded the vitality of the humanities. Their perceived significance among those outside these fields, especially among academic decision-makers and politicians, has been in steady decline (see Pedro 2015 for a witty rendering of the debates).

The evidence and/or arguments are familiar: humanities are not of much utility, they have modest relevance in today's world, they have limited commercial appeal, and they mostly do not easily lend themselves to quantification. Research is underfunded, teaching is understaffed, and the salary gap between scholars in the humanities and in other fields has widened. We witness massive declines in university enrollments for humanities studies, with currently about only eight percent of undergraduates in the US having a major in them, which is a 50 percent reduction since 1966. Obviously such a complex development cannot be reduced to one single factor, but many critical observers see an integrated logic. This has to do with the corporatization of higher education, a vector of the more overarching neoliberal paradigm of societal development that has been hegemonic in the West since the early 1980s. Jay (2014) makes the case that the corporatization of higher education involves a profound transformation towards vocational training. Higher education becomes geared for credentializing, whereby the value of courses and credits are judged in terms of their practical vocational utility. In this setting, it is understandable that the humanities become hit the hardest, especially when the overall trends in knowledge where computational, technological, and mechanical skills are replacing broad-based education that emphasizes history, philosophy, and aesthetics.

We should note, however, that these neoliberal logics are not in any way restricted to universities; they imbue our entire society. Authors such as Sandel (2012) and Nussbaum (2010) demonstrate in various ways how trust, solidarity, and other virtues are bulldozed over by economistic rationality, which seeps into and put price tags on just about all areas of human life. Neoliberalism has become not just a policy horizon but also a cultural motif, shaping social relationships and visions of the good society (see, for example, Couldry, 2010; Young, 2007). Even democracy itself becomes corroded, as normative frameworks that concern justice are subverted, derailing the foundations for democratic political discussion: issues that are normative and political in character become rendered in terms that are economic, technical or administrative in character, undermining the meaningfulness of participation (Brown 2015). This carries with it feelings of disempowerment and ultimately either disengagement or populist 'enragement'.

Thus, I would argue, the importance of the humanities lies also in their service to democracy; they are an essential resource, a compass to help us in piloting the treacherous waters of explicit 
and implicit un- and antidemocratic values, and provide visions of the good society. And with the voices of the traditional humanities less and less heard, much is being lost - perhaps irretrievably. I turn now to a short discussion of the field of Media and Communication Studies, to illustrate more concretely the why our field needs more input from the humanities, and why this has bearing on the life of democracy.

\section{Media and Communication Studies - and Mediatization}

\section{Porous - and expanding - boundaries}

Media Studies was established around the world over the course of a number of decades 1960s-1990s - as proponents of the new field marched out of various 'mother disciples' such as sociology and political science to launch new university departments and research journals. The humanities were in a limited way among some of the 'mother disciplines', notably literature and rhetoric, and to a lesser degree visual aesthetics. Film as an academic discipline is a special case in that while it focuses on 'a medium', it has long maintained its institutional independence from media studies (this distinction seems to be eroding somewhat now with the increasing convergence of media technologies). History has generated a small but robust domain of 'media history' within the field, as is the case with philosophy. I should also mention that the adjacent field of Cultural Studies - which is at least as eclectic and porous as Media Studies - has had a strong humanities profile, especially after it became established in the US (arriving from the UK in the late 1970s-early 1980s). There are some small areas of juxtaposition and overlap between the two fields, and certainly the humanities is well represented in these domains. In sum, though, we can say that while the humanities have always having some sort of presence in the field of Media Studies, its role is a rather minor one. Media Studies remains overwhelmingly social scientific in its orientation.

This tendency is reinforced by the trends in assessment criteria and the templates for journal publishing, where quantitative methods, terse prose, and models of research with origins in the natural sciences have increasingly become the norm in the last decade or so. Generally, it is somewhat easier for researchers in the science sciences to adapt to these publishing templates than for those in the humanities, where longer, descriptive and analytics prose, often in an essayistic style, is more common.

What is of particular relevance today is that the field of Media Studies no longer has a monopoly on its objects of research: scholars from across the range of the social sciences have been increasingly engaging themselves in media research, especially since the advent of the Web. Moreover, some fronts of the field are merging with computer science, telecommunication, informatics, and even AI - artificial intelligence. The very notion of what a 'medium' is - or what 'media' are has been problematized by the technical developments. Some within the field may grumble about this growing expansion and the resultant 'external competition' - and want to guard their institutional interests. Yet intellectually we should laud this development, which adds more scholarly voices and perspectives - even if it risks rendering our distinct academic raison d'être slightly less secure. 
Let us be clear about these developments: for all their significance and the intellectual excitement they generate, for all the interesting results they can deliver, they are for the most part not moving towards the humanities. Rather, within this sprawling field and its interfaces with other disciplines, the direction is all the more towards quantitative trends, where algorithmic analyses of big data phenomena such as Twitter behavior are highly unlikely to critically inquire about the deeper social realities behind the numerical findings. A number of scholars in the field do relate easily to the humanities via their use of qualitative ethnographic approaches and/or their use of textual methodologies such as semiotics, hermeneutics, and discourse analysis. Yet, there seems to be a generational factor here, with these 'softer' approaches in use among older scholars, while younger researchers are all the more likely to follow the quantitative procedures.

\section{Mediatization: meta-processes of late modernity}

There has been a compelling conceptual development in the field over the past decade, which has to do with the perceived scope of the research terrain and with situating the role of media today. Traditionally, in the era of mass communication, media research pivoted on the tri-part division of the institutions of the media, the form and content of their communication, and the consequences or significance of these representations for individuals, organizations, for culture and for society. Though there have been a variety of research paradigms over the years, it was generally taken that mediated communication is a largely one-way, distinct phenomenon emanating from specific organizational entities and impacting on various audiences and publics. However, a rupture began to emerge with the Web: technically, there need not be a difference between 'sender' and receiver'; the 'users' could now be producers as well.

Many aspects of modern life are in some mediated, in that they make use of media; this is not very controversial. But with the notion of mediatization (see Hjarvard 2013; theme issue of Communication Theory 2013), it is argued that the media's interplay with each sector is in some way altering it, and by extension transforming society at large. This is the 'grand' claim; some other versions are more modest. In any case, the revolution brought about by the Internet does lend credence to the claims of mediatization - the Web today does just about touch all phases of personal, organizational, and institutional life- and thus has become a powerful force in constructing the social world (Couldry and Hepp 2016). The low profile of the humanities in this context is unfortunate: the need for their intellectual contribution becomes all the more apparent. This insufficiency becomes evident if we look at some of the key attributes of the Web and how it is used.

\section{Dilemmas of Life Online}

The social sciences tend to stay with questions that are of the more overtly empirical kind, for obvious reasons; larger, more amorphous lines of inquiry are difficult to operationalize for such research. Yet it is these kinds of questions that many people are asking themselves about the Web. For example, even the idea of 'human' is evolving, as our bodies become more bio-technically integrated with digital media; where does this leave the classic notion of the subject? Part of 
the emerging challenge lies in identifying and formulating the important topics of our time in the face of late modern, Web-based mediatization; a number of them are normative-ethical in nature, not merely empirical - and for these reasons I make this appeal for more assistance from the humanities. Certainly there are few social scientists who aim at the broader picture and strive to elicit public debate and policy: the work of Sonia Livingstone in regard to children and the Web is notable here (Livingstne 2009; Livingstone and Sefton-Green 2016). Also the psychologist Aiken (2016) synthesizes many strands of research to problematize how key socio-cultural dimensions are changing via the Web. She examines how the 'cyber effect' impacts on friendship, intimacy, work, education, consumption, even our sense of time. The work of Livingstone, Aiken, and others helpfully offers these problematic perspectives for us to reflect upon - yet we need more help, precisely in how to think about them, how we should deal with them.

Scholars have always found it difficult to get a firm grasp of their own historical era; hindsight is always easier. Yet we cannot postpone our efforts to understand and come to terms with the present to some vague point in the future; we need to tackle many issues now, albeit with an awareness that is always imperfect. The following discussion, in part inspired by a number of stimulating contributions from the humanities, identifies and briefly addresses a range of dilemmas we face as we increasingly live our lives online, and as aspects of our offline lives become increasingly mediatized. Obviously it is impossible to be exhaustive here; what follows can only be suggestive.

\section{Political economy, technical architecture, and automation}

As a way of grounding - in social science manner - an understanding on the ubiquitous and seemingly infinite Web, and particularly social media, a few words about its political economy and technical architecture can be useful. Political economy addresses questions of ownership, control, and the relations of power that derive from these factors. These are the first important things to know about the Web: it is not a neutral communicative space, but is thoroughly structured by power relations. In the online digital world, a few large corporate actors such as Google, Microsoft, Facebook (who also owns YouTube) dominate the Web environment; all are commercial enterprises (only the very small wiki sector has any significant non-commercial actors). This of course raises many issues, not least normative-democratic ones, but for our purposes here, suffice to say that the massive imbalance in power between everyday users and the these corporate entities, and the thoroughly commercial logic of the Web, are decisive in shaping the character of the Web and our experience of it. While we as users can make creative use of the Web, we have little power over its how it is run (see van Dijck 2013).

This becomes apparent if we look at the technical architecture. The technical architecture of the web and social media is, of course, immensely complex; my key point here, however, is quite basic: at whatever aspect of the technical architecture that we look at, we find points of control - points where various actors/stakeholders are in a position to filter, edit, block or exclude what should be the democratic flow of communication for both individuals and social networks. These points include: the overall technical network, the specific device being used, their concrete applications, the actual content being transferred or blocked, and social data (which include users' location, histories of their web usage, applications use, contact histories and so 
forth). Thus for example, with the commercial logic comes a constant accumulation of private data that we provide the Web giants - in the case of Facebook, with our formal consent, in the case of Google, Amazon, etc. by default. This data is packaged, analysed, and sold to many other Web actors. We use the Web, but it also uses us; we should not forget where the definitive power lies. And beyond the commercial logic of the technical architecture we have state surveillance, as was made globally public by the Snowden affair a few years ago. We are always potentially being watched; any lingering sense of privacy is mostly illusionary. Of course this admittedly unpleasant baseline should not deter us from using the Web; rather it should just serve to remind us of its basic contingencies, and as a guide for our usage.

A very different issue emerges from the ever-impressive technical affordances of the Web. It echoes an old dilemma in compelling new ways, yet is rarely discussed today: automation. The theme of automation arose with the Industrial Revolution; the new machines resulted in enormous leaps forward in terms of efficiency and enhanced productivity. And yet, as we know, there was a backlash: Neo-Luddism in the UK during the early years of the 19th century was the most famous manifestation of this revolt against new technologies. While something was gained by these new technologies, it quickly became apparent that something was also lost: the 'deskilling' of crafts people became a major problem. The adage of 'use it or lose it' applies perfectly here: without continually practicing - and passing on to younger generations - their skills, the skills atrophied and disappeared. Moreover, there were other consequences: the machines tended to separate people from actual work, replacing it with stultifying routines. Automation refashions both the work process and the worker; it transforms the character of the whole task, the organization, the roles, attitudes and skills of the people who participate in it. We become in a sense separated from ourselves.

In one of the few texts to apply this logic to digital media, Carr (2014) offers an array of examples of how the new technologies erode not only skills but also imagination, fostering standardized thinking, professional complacency, and a decline in attention when so much which should build on creativity becomes predictable. He depicts what happens to airplane doctors, architects, airline pilots, and even modern Eskimos - who become so dependent on GPS in their snowmobiles that they when the technology fails they become literally - and even fatally - lost. Debates on this theme appeared several decades ago when pocket calculators entered the pockets of many school children - 'How will they do math without these gadgets?' Since then, however, there has been much celebration over the often amazing capacities we have gained, but little discussion about the competencies we may be losing. I am decidedly not making a neo-Neo-Luddite argument here smashing laptops is not on the agenda - but rather asserting that we would benefit from a more sustained analysis of the consequences of our by now taken for granted digital practices. It may be possible to achieve less loss in the face of all the gain, or perhaps reframe our understanding of what is indeed 'gained'.

\section{Abundance, speed, and pathways to knowledge}

There are two particular technical attributes of the web that can impact on its use, the subjectivity of its users, and society more broadly. These are largely taken for granted by now and 
not discussed much anymore - they have merely become features that define the web's admirable character: the abundance of information it makes available and the speed at which information is accessible - and at which it is replaced by new information.

The output on the Web is, from the practical horizons of any user, seemingly inexhaustible. Of course each of us has his/her own areas of interest, networks and sites that we follow, and thereby wall off most of what is 'out there' as not relevant to our purposes. We all develop personal strategies for navigating the daily tsunami of information, the 'infoglut' as Andrejevic (2013) calls it. Yet, as he argues, even as we zero in on just those topics that interest us, we are often still confronted by a vast output and faced by many different perspectives, premises, and conclusions. And even while we tend to adhere to the groupings whose world views we share - we tend to gather in 'bubbles' that often have difficulty communicating with each other boundaries - doubt can set in. And the consequences of doubt operate on the individual, group, and societal levels. Cognitive certainty is dislodged by informational abundance; moreover, as people become all the more media aware and understand the constructed character of mediated representation, suspicion of sources grows. So, to avoid such dissonance, we emotionally wall off those whom we mistrust the most, yet we can still become anxious about what we might be missing. Stress grows; climates of popular debunking emerge, coloured by cynicism.

The danger of the Web's speed are related. Finding and extracting relevant information that one can trust can be difficult in a fast-moving informational environment, but still more challenging is to develop knowledge, in the sense of the critical integration of new information with existing frames of reference, and may involve the modification of these frames. This takes time and effort, both of which become easily marginalized in the digital milieu of the 'the ever new': the present becomes devalued as attention turns to whatever will come next. Decision-making requires reflection, which in turn also demands time. The overall 'speed up' of (late) modern culture, is central theme found in a number of theory-oriented social scientists, including and Harvey (1991) and Virilio (2002). The emphasis on the Web's role in this can be found in more recent writings by some journalists who combine familiarity with current social science research with a strong humanities orientation (Jackson 2009; Colvile 2016). They underscore, among other things, the cognitive stress, lack of focus, as well as eroded linguistic and social capacities that emerge from living and working in the online environment with its accelerating velocity.

Manovich (2013) describes the computer as a 'metamedium', characterized by 'permanent extendibility'. It is capable of translating just about everything into data, and via the use of algorithmic analysis it alters what it means to 'know' something, engendering what he calls software epistemology:

Digital code, data visualization, GIS, information retrieval, machine learning techniques, constantly increasing speed of processors and decreasing costs of storage, big data analytics technologies, social media, and other parts of the modern techno-social universe introduce new ways of acquiring knowledge, and in the process redefine what knowledge is (Manovich 2013:338). 
With new algorithmic methods, one can now even generate new information and knowledge from existing analog sources from the past, such as photos and models. This is called data fusion, and it is clear that it demands some serious rethinking of our traditional epistemologies.

Moreover, in the popular consciousness, not least among policy makers, there has emerged a hegemonic discourse that Mozorov (2013) sees as Internet-centric, a techno-utopian mind-set that assumes that a quick fix is available for social and political problems. Such 'solutionist' thinking results in programmes that throw laptops at underprivileged young people in urban slums in hopes of enhancing their life changes, or installing online chat forums for so that citizens and can communicate with their municipal governments to enhance democracy. And the obvious failures of such strategies do not seem to evoke much critical reflection.

Fernández-Armesto (2010) suggests that historically there are four basic methods that we use in determining what is true: what we feel, what we are told, what we figure out, and what we observe. All four co-exist in various relationships at any point in history. Today, in the viral world of Web information, the first option - that which we feel - is clearly on the rise. With just a little exaggeration, we can say that truth becomes an inner subjective reality, an affective leap, as in the notion of 'truthiness' (a term popularized by the U.S. comedian Stephen Colbert). The affectively attractive becomes the foundation for validity claims about reality, prompting distressed commentary about a 'post-factual' mentality in politics,

Coupled with weak sense of efficacy, it is easy for citizens' assumptions to be psychologically stronger than their critical reasoning, which can open the door to problematic and even dangerous post-rational trajectories. Affect can lead people to find short-cuts to deal with the massive amounts of information and their at times overall ambivalence. This becomes debilitating for the individual, it fosters cognitive closure of groups, and ultimately damaging the critical role of public spheres. It also ferments populism, which can further undercut the dynamics of democracy.

\section{Algorithms, attention, and friends}

In a related intervention, Berardi (2015) contends that while we believe that digital media are empowering us, they are in fact undermining 'the world' that we as a human community know it. He sees the fundamental transition from an alphabetical foundation of knowledge to a digital one as constituting a major historic transition in human civilization. This shift involves on the one hand, an erosion of memory, empathy, sensibility (that is, a fundamental transformation of our subjectivity), and on the other hand, a decreasing capacity to impact in an efficacious manner on this new world:

A world is a projection of meaningful patterns on the surrounding space of lived existence. It is the sharing of a common code whose key lies in the form of life of the community itself.... When the signs proceeding from the environment are no longer consistent and understandable within the frame of the shared code, when sign that convey effectiveness and potency escape the shared cultural code, a civilization ceases to be vital. (p. 331). 
In the online context, what is often now called 'algorithmic culture' (Striphas 2015) signifies the manner in which commercial computational processes (e.g. Google search results) classify and rank people, locations, objects, ideas, and aesthetic works. This has enormous bearing on how 'culture' today is experienced and practiced. Not least these developments increasingly put culture in the hands of giant corporations, who commodify it and erode its public character - which takes us back to the political economy of the Web mentioned above.

While our attention is of commercial concern for corporate Web actors, for ourselves it has to do with central dimensions of our existence. From the horizons of common sense, people have for some years increasingly begun to wonder about the amount of time we devote to screens. Just one little detail among many: according to a recent Neilsen survey in the US the average teenager exchanges about 4000 text messages a month (quoted in Harris, 2014). Whatever the accuracy of this statistic, it evokes scenes familiar to us all: a group lunch where conversation is constantly interrupted by mobile phones, or school yards at recess time where more children are communicating with screens than with each other. Perhaps we are indeed getting better at 'multitasking', but what of the quality of human interaction when attention becomes diffuse and sporadic? Pettman (2106) argues that that not only do social media undercut attention by encouraging distraction, they also fragment us as a society by shuttling us into ever-smaller micro-zones of engagement.

Our social interaction and processes of identity are increasingly tied to our Web experiences. What does it mean for socially when the norm that taking a call or message on the smartphone takes priority over the live conversation one is having? More significantly, we gather and quantifying our 'likes' to enhance our public image, but where does the center of the person now lie? Friendship too is evolving. Previously, friends were largely a personal, private matter. On social media, they become in a sense public, and serve as 'a public' for our manifestations of our identity. Thus, when people put on their Facebook page that they have been taking their kids to a lot of activities, when they post the greetings they sent to their mom on Mother's Day, something happens. On the one hand, that they do these private things is splendid. That they post such acts on Facebook turns them into public performances, a part of the digital presentation of self; an act that will hopefully elicit 'likes'. Where then does the meaning of these acts lie?

Bakardieva (2015) has traced the evolution of online sociality; she sees a process of technical rationalization of 'friendship' - sociality becomes an object of computation and takes on increasingly standardized and trivialized forms and gestures. This has now culminated with the rise of socialbots, i.e. robotized online functions that masquerade as 'friends' online - you are invited to 'friend' somebody - but often that invitation derives not from the person but from the algorithmic conclusion the platform has arrived at. How should we see such developments? What does 'friendship' mean today?

We are more or less always available for our media devices, we are seldom more than a few clicks away from the Web. Indeed, a good deal of our social lives is now experienced or facilitated via the Web, and in the neoliberal era of capitalism, this means that 'the world' is active almost 24/7, which even encroaches on sleep (see Crary 2013). Harris (2014) laments this 'end of absence', and the 'loss of lack' that follows from it - that is, that we are rarely left to our own devices to think, meditate, and reflect, without the assistance of the Web in some way. Harris is 
not a professional humanist, he is a journalist, but articulates in a clear way the concern that many have about 'using vs. losing' some of our most fundamental human capacities.

Access to information has never been greater in human history, but at the same time screen devices alter our relationship to text. The screen 'bias' is towards more visual representation, and, importantly, towards shorter texts. There are undeniable gains here in terms of the speed of information. But the attention required for encountering and processing longer texts seems on the wane among younger generations in many parts of the world, and school results point to a decline in reading skills, prominently among boys. Social scientific data has been presented, discussed, and debated as the extent and depth of these changes, but the larger questions of the fragmentation of attention and transformation of our relationship to the printed word, and to other people, need broader, historically-oriented analyses.

\section{The mediatization of civic engagement}

There is a very large literature dealing with the Web as an institution of the public sphere (see Dahlgren 2013 for an overview), and of course the Web has been an immense asset for democratic participation. However, the initial celebratory atmosphere has subsided, and scholars all the more point to difficulties. For example, against the ideals of reasoned Habermasian deliberation in public sphere, many observers emphasize the barriers to communicative rationality online. Aside from anti-democratic baleful threats and harassment, hate speech, propaganda, and plain uncivil behaviour, just the general communicative environment of the Web is an impediment to such idealizations of the democratic dialogue. As Lievrouw cogently describes the situation:

Media culture in the digital age has become more personal, skeptical, ironic, perishable, idiosyncratic, collaborative, and almost inconceivably diversified, even as established industries and institutions seek to maintain their grip on stable messages and audiences and to extend their business models online (p.214).

What she captures here in fact is some of the definitive textures of the late modern situation, with their cross-currents of power relations and their particular sensibilities and affect. This massive outpouring of user-generated content robustly engenders horizontal communication among citizens, maintaining networks and situating people in various ways towards society and public culture. Yet there are also issues. For example, in regard to journalism, there are all manner of 'citizen journalism' juxtaposing and blending with each other: facts and viewpoints, debates, gossip, nonsense, misinformation, the insightful, the deceptive, the playful, the poetic, are mixed together, scrambling the traditional boundaries between journalism and non-journalism. Where public spheres end and entertainment and consumption take over is not always obvious.

On social media we see a great deal of 'post-Habermaisan', multi-modal expression, where affect and aesthetic dimensions prevail. Emotional aspects such as a passion for justice and visons of the good society are always essential if people are to become politically involved, but the balance with rationality remains ever precarious. When fear, anger, denial, hate, revenge and other sentiments that lurk in the unconscious are in the political driver's seat - even among political leaders (see Žižek 2011) - they can readily be combined with dangerous tendencies towards repression, 
xenophobia, racism, and fascism. Moreover, given that abundance and speed on the Web increase the competition for attention, and as the media environment becomes denser, the odds of getting and holding attention to any message or discussion generally decreases. If we frame this feature in terms of civic engagement, this suggests that people are less likely to engage for longer periods with any given political issue, let alone long range policy horizons; political attention becomes more event-oriented. Protest flares up and vanishes (e.g. Occupy), but the power structures largely do not change.

The Web has become central to democracy; we can do without it, and we have to accept that the modes of political expression mostly do not follow the criteria of communicative rationality. Is all thereby lost? Apparently not, but the danger is there. How are we to deal with the mediatization of democracy in late modernity? In the 1920s John Dewey wrote about the importance of education in shaping democratic citizens; Nussbaum (2010) continues in that that tradition. She underscores the importance of the humanities in schools and universities, and is adamant that ethics and compassion are central, as are fundamental the principles like equality and tolerance. She stresses that the ability to view the world from a variety of perspectives as well as to test alternative sets of values. The role of education - always a challenged - is nonetheless still vital.

If we go beyond the classroom, into the broader societal domain of politics and the Web, democracy still needs to be able to engage citizens to participate and follow its norms. I have written elsewhere about civic cultures as a resource for such engagement Dahlgren 2009). Civic cultures provide taken-for-granted and accessible resources - albeit very vulnerable ones - that can support democratic political agency. Civic cultures are comprised of several dimensions; a central one is knowledge to orient oneself and one's actions in the world. Of course the Web looms massively large here - with all the ambivalence I have suggested above. It can provide an endless flow of facts and information, but the challenge is in part to translate this into knowledge: to sift and filter through the cacophonic, online 'post-rational' public spheres to find resources to add to one's cognitive frameworks.

Ultimately civic cultures must generate civic identities - that allow people to feel that they are empowered civic actors. Through the collective 'doing' of democratic politics with the help of the Web - the sharing, solidarity, trust, encouragement - networked citizens can strengthen their sense of self as political actors (Bennett and Segerberg 2013). Yet online political participation can readily become a privatized activity. The often very loose or non-existent bonds with other active citizens readily help generate a cosy personal comfort zone, a 'solo sphere' characterized by 'slacktivism' and 'clicktivism', yielding situations where actors feel that engaging with the political remains a free-choice option among other leisure pursuits. Such engagement can be quite pleasurable - and does not require the sustained 'work' of serious political participation yet erodes civic culture. Commercialism is nothing new, obviously, but the worry is that in the context of the Web environment, democracy and civic horizons are being seriously marginalized by consumerist values. Indeed, even as people participate politically via social media or websites, they are embedded in a discursive environment, a habitus, that positions them as consumers. 
Certainly more issues can be raised, but hopefully these will suffice to convey a sense of what we need to creatively deal with in regard to the Web and the processes of mediatization. Today, people who were born after ca. 1985 have no direct experience of the pre-digital world. This referent has thus far been foundational in our attempts to understand what the digital transformation of society. One can only - and with some trepidation - imagine the world when no living person has any memory of the time before the digital media became pervasive. I wish to underscore again that to problematize the Web is not to be 'against' it. We do not need to choose between the corporeal reality and the digital one, but rather to critically inquire how we can live 'better' with their interplay, and in the long run impact on policies that shape the Web and its use. In the short term, however, it is more the case of trying to probe how we can enhance our lives with them and despite them. How to live well is a theme that has always been at the heart of the humanities; I hope they join in more in these discussions.

\section{References}

Aiken, M. (2016). The Cyber Effect. London: John Murray.

Bakaedjieva, M. (2015). Rationalizing sociality: an unfinished script for socialbots. The Information Society: An International Journal, 31: 244-256, DOI: 10.1080/01972243.2015.1020197

Bauman, Z. (2007). Liquid times: living in an age of uncertainty. Cambridge: Polity Press.

Bennett, W. L. \& Alexandra, S. (2013). The logic of connective action: digital media and the personalization of contentious politics. New York: Cambridge University Press.

Berardi, F. 'Bifo' (2015). AND: Phenomenology of the end. South Pasadena, CA: semiotext(e). Distributed by MIT Press.

Brown, W. (2015). Undoing the demos: neoliberalism's stealth revolution. New York: Zone Books.

Carr, N. (2104). The glass cage: how our computers are changing us. New York: Norton.

Colvile, R. (2016). The great acceleration. London: Bloomsbury.

Couldry, N. \& Hepp, A. (2016). The mediated construction of reality. Cambridge: Polity Press.

Communication Theory (2013). Special issue: conceptualizing mediatization, vol 23 (3).

Crary, J. (2013). 24/7 Late capitalism and the ends of sleep. London: Verso.

Dahlgren, P. (2009). Media and political engagement. New York: Cambridge University Press.

Dahlgren, P. (2013). The political web: participation, media, and alternative democracy. Basingstoke, UK: Palgrave Macmillan.

Fernández-Armesto, F. (2010). Truth: a history and guide for the perplexed. London: Black Swan.

Harris, M. (2014). The end of absence: reclaiming what we've lost in a world of constant connection. New York: CURRENT/Penguin.

Harvey, D. (1991). The condition of post-modernity. Oxford: Blackwell. 
Hjarvard, S. (2013). The mediatization of culture and society. Abingdon: Routledge.

Holm, P.; Scott, D. \& Jarrick, A. (2014). Humanities world report 2015. Basingstoke: Palgrave.

Jackson, M. (2009). Distracted: the erosion of attention and the coming dark age. New York: Prometheus Books.

Jay, P. (2014). The humanities "crisis" and the future of literary studies. New York: Palgrave Macmillan.

Livingstone, S. (2009). Children and the internet. Cambridge: Polity Press.

Livingstone, S. \& Sefton-Green, J. (2016). The class: living and learning in the digital age. New York: NYU Press.

Manovich, L. (2013). Software takes command. London: Bloomsbury.

Morozov, E. (2013). To save everything, click here. London: Allen Lane.

Nussbaum, M. (2010). Not for profit: why democracy needs the humanities. Princeton, NJ: Princeton University Press.

Pedro, J. (2015). A dialogue between enlightenment liberals and neoliberal elites on the idea of the university. Open Democracy, 21 May. www.opendemocracy.net/joan-pedro/dialoguebetween-enlightenment-liberals-and-neoliberal-elites-on-idea-of-university Accesses 18 May 2016.

Perloff, M. (2001). Crisis in the humanities. University of Buffalo, Electronic Poetry Center. http://epc.buffalo.edu/authors/perloff/articles/crisis.html Accessed 2 June 2016.

Pettman, D. (2106). Infinite distraction: paying attention to social media. Cambridge: Polity.

Sandel, M. (2012). What money can't buy: the moral limits of markets. London: Allen Lane.

Striphas, T. (2015). Algorithmic culture. European Journal of Cultural Studies, 18 (4-5): 395-412.

van Dijck, J. (2013). The culture of connectivity: a critical history of social media.

Virilio, P. (2000). The information bomb. London: Verso.

Young, J. (2007). The vertigo of late modernity. London: Sage.

Žižek, S. (2011). Living in the end of times. London: Verso. 